(2) Open Access Full Text Article

\title{
Personalized treatment strategies in glioblastoma: MGMT promoter methylation status
}

This article was published in the following Dove Press journal:

OncoTargets and Therapy

26 September 2013

Number of times this article has been viewed

\author{
Niklas Thon' \\ Simone Kreth ${ }^{2}$ \\ Friedrich-Wilhelm Kreth' \\ 'Department of Neurosurgery, \\ ${ }^{2}$ Department of Anaesthesiology, \\ Hospital of the University of Munich, \\ Campus Grosshadern, Munich, \\ Germany
}

\begin{abstract}
The identification of molecular genetic biomarkers considerably increased our current understanding of glioma genesis, prognostic evaluation, and treatment planning. In glioblastoma, the most malignant intrinsic brain tumor entity in adults, the promoter methylation status of the gene encoding for the repair enzyme O6-methylguanine-DNA methyltransferase (MGMT) indicates increased efficacy of current standard of care, which is concomitant and adjuvant chemoradiotherapy with the alkylating agent temozolomide. In the elderly, $M G M T$ promoter methylation status has recently been introduced to be a predictive biomarker that can be used for stratification of treatment regimes. This review gives a short summery of epidemiological, clinical, diagnostic, and treatment aspects of patients who are currently diagnosed with glioblastoma. The most important molecular genetic markers and epigenetic alterations in glioblastoma are summarized. Special focus is given to the physiological function of DNA methylation - in particular, of the $M G M T$ gene promoter, its clinical relevance, technical aspects of status assessment, its correlation with $M G M T$ mRNA and protein expressions, and its place within the management cascade of glioblastoma patients.
\end{abstract}

Keywords: glioblastoma, $M G M T$, temozolomide, personalized treatment, outcome

\section{Glioblastoma}

Diffuse gliomas are heterogeneous neoplasms that account for half of all intrinsic brain tumors. Histological grading of these tumors according to the classification system of the World Health Organization (WHO) provides a basis for defining groups of patients for clinical assessment, but also predicts the clinical behavior of the respective neoplasm with direct impact on the applied treatment regimes. WHO grade IV gliomas are characterized by high cellularity, cellular pleomorphism, nuclear atypia, brisk mitotic activity, microvascular proliferation, and necrosis. ${ }^{1}$ They account for $50 \%-60 \%$ of all astrocytic gliomas, with an increasing incidence of currently three to five new cases per 100,000 patient-years. $^{2}$ The cause for glioblastoma development is not clear. Some authors speculate that cytomegalovirus infection may drive the oncogenic process by modulating growth factor and receptor expressions in gliomas. ${ }^{3}$ Clinically, these tumors are rapidly progressive and ultimately fatal, with a median survival of only 15 months in trial populations. ${ }^{4}$ Primary glioblastomas develop with only a short clinical history and without evidence of a previous lesion of lower malignancy. They account for the vast majority of glioblastomas in older patients. Morphologically, they cannot be distinguished from about 5\%-10\% of glioblastomas that develop in younger patients below the age of 50 years by progression from a pre-existing lower-grade glioma.,
Correspondence: Niklas Thon

Department of Neurosurgery,

University of Munich, Campus

Grosshadern, Marchioninistrasse 15

81377 Munich, Germany

Tel +498970950

Fax +49897095 6554

Email niklas.thon@med.uni-muenchen.de 
These secondary glioblastomas differ significantly in their genetic profiles from primary glioblastomas. ${ }^{7,8}$

\section{The diagnostic challenge}

Routine diagnosis critically relies on magnetic resonance imaging (MRI) that frequently exhibits contrast enhancement of the lesion in $\mathrm{T}_{1}$-weighted sequences accompanied by perifocal edema as being depicted on $\mathrm{T}_{2}$-/fluid-attenuated inversion recovery-weighted images. Lack of focal contrast enhancement, however, does not exclude grade IV histology. ${ }^{9,10}$ The vast majority of glioblastomas develop in the cerebral hemispheres. However, the highly infiltrative growing pattern frequently causes tumor spread into the basal ganglia or even the contralateral hemisphere, with unfavorable effects on patients' outcome. Glioblastomas with primary location in the cerebellum, brain stem, or myelon are rare. Metabolic imaging such as positron emissions tomography (PET) utilizing amino acid tracers (eg, $\mathrm{O}-\left[2-\left\{{ }^{18} \mathrm{~F}\right\}\right.$ fluoroethyl]-1-tyrosine) is increasingly used to assess differential diagnosis, ${ }^{11,12}$ biological tumor volume, and intratumoral heterogeneity, ${ }^{10}$ and to monitor therapy. ${ }^{13-15}$ Mainly due to its limited availability and associated costs, metabolic imaging has not yet been routinely implemented into a current standard of care algorithm for glioblastoma patients. Ultimately, tissue samples are needed for definite histological diagnosis. Neuropathological evaluation of gliomas, however, suffers from significant interobserver variability, particularly in the distinction of grade III and grade IV histology and the determination of an oligodendroglial cell component. ${ }^{16}$

\section{Current treatment concepts}

More recently, some progress has been achieved in the treatment of glioblastoma patients. A companion prospective multicenter study performed by the European Organization for Research and Treatment of Cancer (EORTC) and the National Cancer Institute of Canada (NCIC) has shown that the addition of the alkylating agent temozolomide to radiotherapy improved 2-year survival of patients with newly diagnosed malignant glioma (mainly glioblastoma) from $11.0 \%$ to $27.3 \%$, 3-year survival from $4.4 \%$ to $16.0 \%$, and 5 -year survival from $1.9 \%$ to $9.8 \%$, respectively. ${ }^{17,18}$ Temozolomide is an orally administered chemotherapy with limited side effects and a good penetration of the blood-brain barrier. It prevents replication by alkyl group-mediated crosslinking of DNA. ${ }^{19}$ Currently, radiotherapy with concomitant and adjuvant temozolomide is the gold standard for patients with newly diagnosed glioblastoma. ${ }^{4}$ Most recent results from the Phase III study AVAglio, evaluating the addition of the antiangiogenic agent bevacizumab to combined chemoradiotherapy with temozolomide, have indicated favorable effects on progression-free survival (median 10.6 months versus 6.2 months) and duration of good clinical performance (Karnofsky performance status $\geq 70 ; 9$ months versus 6 months). ${ }^{20,21}$ However, no effect on overall survival was observed. In the elderly, the best treatment strategy is highly influenced by the patient and tumor-related factors and ranges from combined chemoradiotherapy with temozolomide for highly selected patients with good clinical performance status to either radiotherapy or temozolomide treatment alone, and supportive care only. ${ }^{22-28}$

Open tumor resection also represents one of the mainstays in glioblastoma treatment and is usually considered the first step within the management algorithm. ${ }^{29,30}$ The highly infiltrative growing pattern of glioblastomas into surrounding brain tissues explains that curative resection generally cannot be achieved. However, there is good evidence that overall survival is improved if early postoperative MRI depicts that no residual contrast-enhancing tumor mass has been left in situ ("gross total resection"). ${ }^{31-35}$ In a community setting, complete resection is achieved in about $40 \%-45 \%$ of patients, a similar proportion receives incomplete resection, and about $10 \%-20 \%$ are diagnosed by biopsy only. ${ }^{21}$ The number of patients without residual tumors can be significantly increased if microsurgical tumor removal is performed with the aid of 5-aminolevulinic acid and intraoperative MRI. ${ }^{31,36}$ The prognostic impact of incomplete resection is poorly defined. ${ }^{30}$ Favorable impacts on survival rates have been suggested if at least $78 \%$ of contrast-enhancing tumor volume has been successfully removed.$^{37}$ However, this and other studies did not compare the impact of incomplete resection with biopsy only, and there is some evidence that biopsy only with early transferral to chemoradiotherapy might be appropriate in selected patients in whom even partial resection bears a considerable risk of surgery-related sequalae. ${ }^{38}$ In patients suffering from clinical deterioration due to a large space-occupying tumor burden, decompressive surgery should be attempted. ${ }^{30}$

Although the use of temozolomide has improved outcome considerably, almost all patients suffer from recurrent disease. Local tumor progression (within $3 \mathrm{~cm}$ from the margin) is the predominant pattern $(93.5 \%)$ of treatment failure..$^{39-42}$ In general, tumor recurrence is associated with poor outcome as treatment options are limited..$^{43}$ Approximately one-quarter of patients with glioblastoma develop a type of recurrence that allows for local treatment including repeated 
surgical resection. ${ }^{44}$ Although reoperation might improve post-recurrence survival in selected cases, its value must be counterbalanced by the risk of surgery-related morbidity and mortality. ${ }^{45,46}$ Other local treatment options include stereotactic radiosurgery for small lesions, hypofractionated radiotherapy protocols, even for larger recurrent tumors, and any combination of local irradiation and chemotherapy. ${ }^{43}$ Systemic therapy is generally considered essential for recurrent tumors. Various antineoplastic agents have been tested. Efficacy, however, is generally hampered by the broad chemoresistance of glioblastoma cells, in parallel with the limited bioavailability of most drugs inside the central nervous system. The most important approaches include rechallenge regimes with dose-intensified temozolomide and non-temozolomide-containing regimes. ${ }^{43,47}$ Since 2009 the monoclonal antibody to vascular endothelial growth factor bevacizumab has gained US Food and Drug Administration approval for recurrent glioblastoma based on response rate, with favorable effects relative to historical controls from noncomparative Phase II trials. ${ }^{48,49}$ The rejection in Europe, however, was based on the absence of a randomized trial with a bevacizumab-free control arm. ${ }^{47}$ Other targeted approaches address the epidermal growth factor receptor, mammalian target of rapamycin, histone deacetylase, and many other structures in recurrent glioblastoma. However, postrecurrence survival rarely exceeds $6-9$ months in most clinical study populations.

\section{The prognostic network of glioblastoma patients}

In glioblastoma, the patient's prognosis and response to therapy are highly influenced by clinical and molecular genetic factors that are increasingly used for prognostic profiling and individualized risk-adapted treatment considerations. ${ }^{50}$ Classical phenotypical traits correlating with favorable survival are younger age, good performance status, and noneloquent circumscribed tumor formations. , $35,51-53^{-1}$ However, these conventional prognostic factors do not necessarily account for the highly variable clinical courses of glioblastoma patients.

Molecular biomarkers have improved our understanding of glioma development, are increasingly exploited for glioblastoma subclassification, and have gained prognostic/ predictive relevance. From a clinical perspective, a biomarker should be highly sensitive and specific in providing information relevant for diagnosis, prognosis, or therapy of a disease. So far, only a few biomarkers have gained clinical relevance in glioblastoma patients.

\section{Genetic markers relevant for glioma patients}

Mutations in the gene encoding for the Krebs cycle enzyme, isocitrate dehydrogenase (IDH), have been identified as one of the earliest molecular events in the pathway of glioma genesis. They are frequent in grade II/III astrocytomas, oligoastrocytomas, and oligodendrogliomas, and can be used to differentiate primary and secondary glioblastomas. ${ }^{6,54,55}$ These findings suggest that histologically differently appearing tumor subclasses might share common precursor cells, and that histologically indistinguishable tumors (eg, primary versus secondary glioblastomas) could be separated into biologically distinct subclasses. $I D H$ point mutations are predominantly found at the arginine 132 (IDH1), but can also occur at arginine 172 (IDH2). These mutations cause alterations in the active site of the $I D H$ enzyme and result in increased production of 2-hydroxyglutarate, which is associated with an increased risk of cancer and glioma progression..$^{56} \mathrm{IDH} 1$ mutations are associated with favorable outcome in WHO grade III and IV malignant gliomas. ${ }^{57,58}$ Notably, patients with $I D H 1$ wild-type anaplastic astrocytoma WHO grade III experience even worse outcome than those with glioblastomas WHO grade IV harboring an IDH1 mutation..$^{59}$ The prognostic impact of the IDHI status in WHO grade II astrocytomas is more controversial but might be associated with unfavorable outcome until tumor progression occurs. ${ }^{60}$ TP53 mutations are frequent in $70 \%$ of secondary glioblastomas and seldom in primary glioblastomas. ${ }^{61}$ TP53 modulates cell-cycle control in tumor cells and has been associated with unfavorable outcome in grade II gliomas. ${ }^{62,63}$ Loss of heterozygosity on chromosome arms $1 p$ and $19 q(\mathrm{LOH} 1 p / 19 q)$ is frequent in oligodendroglial tumors, and has been associated with increased chemosensitivity in grade III gliomas. ${ }^{64,65}$ Whether $1 p$ - and $19 q$-codeleted tumors have a less aggressive natural course than noncodeleted tumor has not been clarified so far. In glioblastoma, $\mathrm{LOH} 1 p / 19 q$ is rare $(\sim 5 \%) \cdot{ }^{50}$ However, an oligodendroglioma-like component (GBM-O) is seen in $15 \%$ of all glioblastomas and has been associated with improved clinical outcome. ${ }^{66}$ Whether a favorable outcome in these patients is also influenced by $\mathrm{LOH} 1 p / 19 q$ has not been unequivocally clarified. ${ }^{67,68}$ Other molecular genetic markers, such as PTEN mutation, epidermal growth factor receptor variant III and $C D K 4$ amplifications, and CDKN2 A homozygous deletion, can be used to separate primary from secondary glioblastomas, indicating different biology and cells of origin. ${ }^{8,69}$ However, these markers have not yet gained prognostic relevance in clinical trials. ${ }^{70}$ 
Besides a mutated $I D H 1$ status and $L O H 1 p / 19 q$, methylation of the promoter region of the O6-methylguanineDNA methyltransferase (MGMT) gene has been correlated with favorable outcome in malignant glioma patients.

\section{Physiological function of DNA methylation and its role in glioma formation}

One of the first and most important epigenetic modifications studied in humans is DNA methylation, which describes the covalent addition of a methyl group preferentially at the $5^{\prime}$-position of a cytosine or guanine nucleotide. These $\mathrm{CpG}$ dinucleotides tend to cluster to so-called $\mathrm{CpG}$ islands, being located in the promoter regions of more than half of all human genes, or to $\mathrm{CpG}$ island shores, which are regions of lower $\mathrm{CpG}$ density that lie in close proximity to $\mathrm{CpG}$ islands. ${ }^{71,72}$ DNA methylation is mediated by the DNA methyltransferase family of enzymes. These enzymes catalyze the transfer of a methyl group from S-adenosyl methionine to DNA and are responsible for maintaining the methylation pattern (eg, during DNA replication). ${ }^{73,74}$ Generally, $\mathrm{CpG}$ methylation is closely associated with transcriptional inactivation. Less frequently, when occurring at gene bodies, it can cause transcriptional activation. Genome-wide methylation patterns have been associated with tumor initiation and progression in several cancers, including colon, breast, and lung. ${ }^{75,76}$

\section{DNA methylation in glioblastoma}

The genome of glioblastoma cells shows broad hypomethylation with specific areas of hypermethylation. ${ }^{77-80}$ This characteristic pattern has been associated with increased genetic instability, silencing of tumor suppressors such as TP53 and PTEN, and activation of oncogenes. Hypermethylation mostly occurs at the promoter $\mathrm{CpG}$ island of genes that are associated with tumor suppression, ${ }^{81,82}$ DNA repair, ${ }^{83}$ cellcycle regulation, ${ }^{84}$ apoptosis, ${ }^{85,86}$ invasion, ${ }^{87,88}$ and migration. ${ }^{89}$ Interestingly, the methylation patterns differ between gliomas of WHO grade II-IV. ${ }^{90}$

The Cancer Genome Atlas project has identified a glioma $\mathrm{CpG}$ island methylation phenotype that correlated with younger age, a proneural gene expression profile, ${ }^{91}$ and longer overall survival in glioblastoma patients. ${ }^{92}$ Moreover, a high frequency of $I D H I$ mutations indicates a link between metabolic alterations and epigenetic modification in these tumors. ${ }^{93,94}$ Increased production of the metabolite 2-hydroxyglutarate interferes with $\alpha$-ketoglutarate-dependent enzyme, including histone demethylases and the TET family of 5-methylcytosine hydroxylases, ${ }^{56,95}$ which causes genome-wide histone modifications, ${ }^{96}$ and alterations of DNA methylation status ${ }^{97}$ in malignant glioma cells. ${ }^{98,99}$

\section{MGMT promoter methylation in glioblastoma}

In glioblastoma, promoter methylation of the gene encoding for $M G M T$ is undoubtedly the genetic fingerprint with highest impact on clinical practice. The MGMT gene is located at chromosome 10q26 and codes for a ubiquitously expressed suicide DNA repair enzyme that removes alkyl adducts from the $\mathrm{O}^{6}$-position of guanine. ${ }^{100} \mathrm{As}^{6}$-alkylated guanine leads to double-strand breaks and base mispairing, thereby inducing apoptosis and cell death, $M G M T$ protects normal cells from carcinogens. Unfortunately, it also protects tumor cells from normally lethal effects of chemotherapy with alkylating agents such as temozolomide. ${ }^{100}$ MGMT is consumed when counteracting TMZ-induced DNA damage, and it has been predicted that the intracellular level of $M G M T$ correlates with chemoresistance. ${ }^{101}$ However, analysis of $M G M T$ protein expression in glioblastoma tissue by immunohistochemistry failed to correlate with survival under chemoradiotherapy. ${ }^{102}$

\section{Clinical relevance}

Methylation of the MGMT promoter is found in 35\%-45\% of malignant gliomas (WHO grades III and IV) and in about $80 \%$ of WHO grade II gliomas. ${ }^{60,103}$ MGMT methylated and unmethylated glioblastomas seem to differ in primary location, ${ }^{104}$ pattern of contrast enhancement ${ }^{105}$ and the apparent diffusion coefficient in MRI analysis, ${ }^{106}$ the incidence of pseudoprogression, ${ }^{107,108}$ and pattern of recurrence as determined by ${ }^{18}$ FET-PET imaging. ${ }^{109}$ However, none of these methods sufficiently allows for noninvasive determination of $M G M T$ promoter methylation status for the individual patient. ${ }^{104,105,110}$

The methylation status of the $M G M T$ promoter has been identified as a strong and independent predictive factor of favorable survival in glioblastoma patients undergoing chemotherapy with alkylating agents. ${ }^{103,111-113}$ The median survival for patients with a methylated $M G M T$ promoter was 21.7 months compared with 12.7 months for patients without. Accordingly, a high frequency of $M G M T$ promoter methylation was noted in long-term survivors of glioblastoma who received repetitive alkylating chemotherapy during the course of the disease. ${ }^{23,114}$ Generally, carriers of the methylated form of the MGMT promoter respond substantially better to therapy with temozolomide as compared 
with those with an unmethylated $M G M T$ promoter. ${ }^{17,58}$ This predominant influence of $M G M T$ promoter methylation is independent of surgical treatment. Moreover, a methylated $M G M T$ promoter status seems to stratify outcome even in the recurrent disease. ${ }^{115}$ Postrecurrence survival was better in those $M G M T$ methylated patients who receive alkylating therapy for recurrent disease. ${ }^{115}$ However, a methylated MGMT promoter status does not influence outcome in solely irradiated glioblastoma patients (without alkylating therapy), whereas in grade III gliomas favorable outcome in methylated patients seems to be irrespective of the applied treatment regime. ${ }^{58,116}$ It is currently unclear, however, whether this observation indicates a true prognostic value for $M G M T$ methylation in all grade III gliomas. ${ }^{117}$ In grade II gliomas, MGMT promoter methylation shows a Janus head-like correlation with shortened progression-free survival but prolonged overall survival under radio and/or chemotherapy. ${ }^{61}$

\section{Determination of the MGMT promoter methylation status}

Currently, there is no consensus about the most suitable technique for determination of the MGMT promoter methylation status. This concerns both the tissue sampling technique as well as the molecular assays currently used in the clinical setting. ${ }^{30} M G M T$ promoter methylation status can be efficiently determined even from small $\left(1 \mathrm{~mm}^{3}\right)$ formalin-fixed, paraffin-embedded tissue samples obtained from stereotactic biopsy procedures. ${ }^{23}$ Analysis of $M G M T$ promoter methylation status of multiple tissue samples harvested from serial biopsy procedures throughout entire tumor volumes has proven that this molecular fingerprint is homogeneous in glioblastoma formations. ${ }^{23}$ Notably, only vital (non-necrotic) tumor specimens must be used for subsequent analysis in order to avoid false-negative results. ${ }^{23,118}$ Analyses from paired tumor samples harvested from primary and recurrent glioblastomas revealed that $M G M T$ promoter methylation status is unchanged during the course of the disease. ${ }^{115}$

In respect of the currently available methods for $M G M T$ testing, nonquantitative methylation-specific polymerase chain reaction (MSP) ${ }^{119}$ seems to be the most appropriate one in a clinical setting. ${ }^{120,121}$ Commonly, two pairs of primers each specific to either the methylated or the unmethylated $M G M T$ promoter region - are used for MSP as originally described by Esteller et al. ${ }^{122}$ However, discrepancies exist between sequencing analyses ${ }^{123}$ and results from MSP. Tumors classified as "unmethylated" by MSP could turn out to be "methylated" or at least "partially methylated" using sequencing analysis. ${ }^{124} \mathrm{~A}$ recent study systematically analyzed the impact of specific $C p G$ sites within the $M G M T$ promoter on the transcriptional regulation of $M G M T$ using a luciferase reporter assay. ${ }^{125}$ This study revealed that MSP is located within the optimal region for $M G M T$ testing. However, the study also showed that substitution of a single $C p G$ outside the MSP region almost completely inhibited the promoter activity. Also, there was a high variability regarding the methylated positions. Hence, promoter methylationmediated gene silencing seems to be strongly dependent on the location of the methylated $C p G$ s and the extent of the overall $C P G$ island methylation, which considerably complicates classification. ${ }^{17,126}$ Given these facts, determination of all individual $C p G$ sites of the recently identified optimal region might predict the transcriptional activity and sensitivity to alkylating substances more confidently. ${ }^{117}$ More clinical data are needed to support this assumption.

MGMT determination by immunohistochemistry has also been suggested. However, this method lacks standardization, reproducibility, and correlation with outcome.

\section{MGMT promoter methylation and RNA expression}

Differential regulation of $M G M T$ mRNA expression might also explain why $M G M T$ promoter methylation is not unequivocally linked to a favorable treatment response. It has been shown that not all patients with a methylated promoter reveal similar response to temozolomide treatment and that a considerable number of unmethylated tumors experienced a surprisingly favorable course of the disease. ${ }^{127}$ These observations could be explained by discordant correlations between $M G M T$ promoter methylation (as being determined by both MSP and sequencing analysis) and MGMT mRNA expression pattern. High (low) mRNA $M G M T$ expression was detected in approximately $25 \%$ of glioblastomas despite a methylated (unmethylated) $M G M T$ promoter. Notably, those patients with low transcriptional activity exhibited a better treatment response, which was independent of $M G M T$ promoter methylation. These observations were confirmed by another study verifying low MGMT immunostaining in 23\% of unmethylated patients and high $M G M T$ expression in $8 \%$ of methylated patients. ${ }^{128}$ The underlying mechanisms of discordance still remain unclear. It has been hypothesized that low MGMT expression levels combined with an unmethylated promoter might result from transcript destabilization and/or transcriptionrepressing factors, such as miRNA regulation or histone modifications. ${ }^{127,129}$ Additionally, variable outcomes in the unmethylated glioblastoma population could be mediated by 
further factors, such as a heterogeneous expression pattern of the DNA repair enzyme $A P N G$, which confers resistance to temozolomide treatment. ${ }^{130}$

\section{MGMT for decision making in glioblastoma patients}

$M G M T$ promoter methylation status has been established as an important clinical biomarker in neuro-oncology. Accordingly, determination of $M G M T$ promoter methylation status is of utmost interest for prognostication of adult patients suffering from newly diagnosed glioblastoma. This also includes those patients with nonresectable tumors that undergo biopsy only. However, with a lack of established alternative treatment options and in the absence of any clinical consequence of routine determination of the MGMT promoter, methylation status does not yet add to the management of glioblastoma patients outside clinical trials. In the absence of potent alternative drugs, temozolomide chemotherapy should not be withheld from unmethylated glioblastoma patients younger than 70 years of age in general practice. Moreover, discordant responses even within the subgroups of methylated and unmethylated patients indicate that treatment decision in respect of chemotherapy cannot be based on this biomarker alone.

The effects of $M G M T$ promoter methylation in malignant gliomas seem to also be dependent on WHO grading. In anaplastic glioma, favorable progression-free survival in MGMT methylated patients was also seen under radiation therapy alone. ${ }^{58}$ This difference might be explained by the high incidence of other favorable molecular markers in WHO grade III gliomas, such as IDH1 mutation, 1p/19q deletion, or yet to be identified novel aberrations.

\section{MGMT in the elderly}

In the older glioblastoma patient, $M G M T$ promoter methylation status is on the verge of entering clinical decision making. Combined chemoradiotherapy comprising temozolomide might be too toxic for the elderly, with increased side effects. ${ }^{22,131,132}$ For the elderly with malignant glioma, two recently published Phase III trials have evaluated the place of dose-dense/conventional temozolomide regimes alone as compared with conventional/hypofractionated radiotherapy. ${ }^{25,133}$ Overall survival in methylated patients was better if temozolomide treatment was applied, whereas in unmethylated patients radiotherapy alone was more effective. Thus, MGMT promoter methylation is an important biomarker for personalized treatment strategies in the elderly subpopulation.

\section{MGMT and clinical trials}

$M G M T$ promoter methylation testing has recently been introduced as a marker for patient selection within clinical trials. ${ }^{113,134-137}$ Results from a Phase I/IIA trial for cilengitide have shown that treatment effects were better in $M G M T$ promoter methylated patients. ${ }^{138}$ Accordingly, the ongoing Cilengitide, Temozolomide, and Radiation Therapy in Treating Patients With Newly Diagnosed Glioblastoma and Methylated Gene Promoter Status (CENTRIC) study (NCT00689221) was one of the first prospective multicenter studies that evaluated alternative treatment (cilengitide, temozolomide, and radiation therapy) in MGMT methylated glioblastoma patients only. The Radiation Therapy Oncology Group (RTOG) 0825 trial also incorporated $M G M T$ promoter methylation testing for primary glioblastoma patients who underwent bevacizumab administered with radiotherapy compared with conventional concurrent chemoradiotherapy (temozolomide). ${ }^{139}$

\section{Conclusion}

There is an urgent need to identify biomarkers in malignant glioma patients in order to indicate patients at risk of tumor relapse, treatment failure, or adverse events, and to allow for prognostication and clinical decision making. ${ }^{122}$ Currently, the methylation status of the MGMT gene promoter seems to separate different subtypes of malignant glioma patients and will certainly influence future studies in respect of stratification of patient groups who are more likely to respond to a certain therapy. The usefulness of $M G M T$ testing in a routine clinical setting will be of fundamental relevance when distinct treatment strategies for methylated and unmethylated glioblastoma patients will be available.

\section{Disclosure}

The authors report no conflicts of interest in this work.

\section{References}

1. Louis DN, Ohgaki H, Wiestler OD, et al. The 2007 WHO classification of tumours of the central nervous system. Acta Neuropathol. 2007;114(2):97-109.

2. Crocetti E, Trama A, Stiller C, et al. Epidemiology of glial and non-glial brain tumours in Europe. Eur J Cancer. 2012;48(10): 1532-1542.

3. Sampson JH, Mitchell DA. Is cytomegalovirus a therapeutic target in glioblastoma? Clin Cancer Res. 2011;17(14):4619-4621.

4. Preusser M, de Ribaupierre S, Wöhrer A, et al. Current concepts and management of glioblastoma. Ann Neurol. 2011;70(1):9-21.

5. Scherer HJ. A critical review: the pathology of cerebral gliomas. J Neurol Psychiatry. 1940;3(2):147-177.

6. Nobusawa S, Watanabe T, Kleihues P, Ohgaki H. IDH1 mutations as molecular signature and predictive factor of secondary glioblastomas. Clin Cancer Res. 2009;15(19):6002-6007. 
7. Watanabe K, Tachibana O, Sata K, Yonekawa Y, Kleihues P, Ohgaki H. Overexpression of the EGF receptor and p53 mutations are mutually exclusive in the evolution of primary and secondary glioblastomas. Brain Pathol. 1996;6(3):217-223.

8. Ohgaki H, Dessen P, Jourde B, et al. Genetic pathways to glioblastoma: a population-based study. Cancer Res. 2004;64(19):6892-6899.

9. Barker FG 2nd, Chang SM, Huhn SL, et al. Age and the risk of anaplasia in magnetic resonance-nonenhancing supratentorial cerebral tumors. Cancer. 1997;80(5):936-941.

10. Kunz M, Thon N, Eigenbrod S, et al. Hot spots in dynamic (18)FETPET delineate malignant tumor parts within suspected WHO grade II gliomas. Neuro Oncol. 2011;13(3):307-316.

11. Pöpperl G, Kreth FW, Mehrkens JH, et al. FET PET for the evaluation of untreated gliomas: correlation of FET uptake and uptake kinetics with tumour grading. Eur J Nucl Med Mol Imaging. 2007;34(12): 1933-1942.

12. Jansen NL, Schwartz C, Graute V, et al. Prediction of oligodendroglial histology and LOH 1p/19q using dynamic [18F]FET-PET imaging in intracranial WHO grade II and III gliomas. Neuro Oncol. 2012;14(12):1473-1480.

13. Pöpperl G, Goldbrunner R, Gildehaus FJ, et al. O-(2-[18F]fluoroethyl)L-tyrosine PET for monitoring the effects of convection-enhanced delivery of paclitaxel in patients with recurrent glioblastoma. Eur J Nucl Med Mol Imaging. 2005;32(9):1018-1025.

14. Jansen NL, Suchorska B, Schwarz SB, et al. [18F]fluoroethyltyrosinepositron emission tomography-based therapy monitoring after stereotactic iodine- 125 brachytherapy in patients with recurrent high-grade glioma. Mol Imaging. 2013;12(3):137-147.

15. Gotz I, Grosu AL. [(18)F]FET-PET imaging for treatment and response monitoring of radiation therapy in malignant glioma patients: a review. Front Oncol. 2013;3:104.

16. van den Bent MJ. Interobserver variation of the histopathological diagnosis in clinical trials on glioma: a clinician's perspective. Acta Neuropathol. 2010;120(3):297-304.

17. Stupp R, Mason WP, van den Bent MJ, et al. Radiotherapy plus concomitant and adjuvant temozolomide for glioblastoma. $N$ Engl J Med 2005;352(10):987-996.

18. Stupp R, Hegi ME, Mason WP, van den Bent MJ, Taphoorn MJ, Janzer RC, et al. Effects of radiotherapy with concomitant and adjuvant temozolomide versus radiotherapy alone on survival in glioblastoma in a randomised phase III study: 5-year analysis of the EORTC-NCIC trial. Lancet Oncol. 2009;10(5):459-466.

19. Thomas RP, Recht L, Nagpal S. Advances in the management of glioblastoma: the role of temozolomide and MGMT testing. Clin Pharmacol. 2013;5:1-9.

20. Chinot OL, de La Motte Rouge T, Moore N, et al. AVAglio: Phase 3 trial of bevacizumab plus temozolomide and radiotherapy in newly diagnosed glioblastoma multiforme. Adv Ther. 2011;28(4): 334-340.

21. Chinot O, Wick W, Mason W, et al. Phase III trial of bevacizumab added to standard radiotherapy and temozolomide for newly-diagnosed glioblastoma: mature progression-free survival and preliminary overall survival results in AVAglio. Neuro Oncol. 2012;14:101-103.

22. Fiorentino A, Balducci M, De Bonis P, et al. Can elderly patients with newly diagnosed glioblastoma be enrolled in chemoradiotherapy trials? Am J Clin Oncol. February 5, 2013. [Epub ahead of print.]

23. Thon N, Eigenbrod S, Grasbon-Frodl EM, et al. Predominant influence of MGMT methylation in non-resectable glioblastoma after radiotherapy plus temozolomide. J Neurol Neurosurg Psychiatry. 2011;82(4):441-446.

24. Wiestler B, Claus R, Hartlieb SA, et al. Malignant astrocytomas of elderly patients lack favorable molecular markers: an analsis of the NOA-08 study collective. Neuro Oncol. 2013;15(8):1017-1026.

25. Wick W, Platten M, Meisner C, et al. Temozolomide chemotherapy alone versus radiotherapy alone for malignant astrocytoma in the elderly: the NOA-08 randomised, phase 3 trial. Lancet Oncol. 2012;13(7): 707-715.
26. Gállego Pérez-Larraya J, Ducray F, Chinot O, et al. Temozolomide in elderly patients with newly diagnosed glioblastoma and poor performance status: an ANOCEF phase II trial. J Clin Oncol. 2011;29(22): 3050-3055.

27. Gulati S, Jakola AS, Johannesen TB, Solheim O. Survival and treatment patterns of glioblastoma in the elderly: a population-based study. World Neurosurg. 2012;78(5):518-526.

28. Niyazi M, Schwarz SB, Suchorska B, Belka C. Radiotherapy with and without temozolomide in elderly patients with glioblastoma. Strahlenther Onkol. 2012;188(2):154-159.

29. Stupp R, Tonn JC, Brada M, Pentheroudakis G. High-grade malignant glioma: ESMO Clinical Practice Guidelines for diagnosis, treatment and follow-up. Ann Oncol. 2010;21 (Suppl 5):v190-v193.

30. Tonn JC, Thon N, Schnell O, Kreth FW. Personalized surgical therapy. Ann Oncol. 2012;23 (Suppl 10):x28-x32.

31. Stummer W, Pichlmeier U, Meinel T, Wiestler OD, Zanella F, Reulen HJ. Fluorescence-guided surgery with 5-aminolevulinic acid for resection of malignant glioma: a randomised controlled multicentre phase III trial. Lancet Oncol. 2006;7(5):392-401.

32. Stummer W, Tonn JC, Mehdorn HM, et al. Counterbalancing risks and gains from extended resections in malignant glioma surgery: a supplemental analysis from the randomized 5-aminolevulinic acid glioma resection study. Clinical article. J Neurosurg. 2011;114(3): 613-623.

33. Laws ER, Parney IF, Huang W, et al. Survival following surgery and prognostic factors for recently diagnosed malignant glioma: data from the Glioma Outcomes Project. J Neurosurg. 2003;99(3):467-473.

34. Oszvald A, Güresir E, Setzer M, et al. Glioblastoma therapy in the elderly and the importance of the extent of resection regardless of age. J Neurosurg. 2012;116(2):357-364.

35. Lacroix M, Abi-Said D, Fourney DR, et al. A multivariate analysis of 416 patients with glioblastoma multiforme: prognosis, extent of resection, and survival. J Neurosurg. 2001;95(2):190-198.

36. Senft C, Bink A, Franz K, Vatter H, Gasser T, Seifert V. Intraoperative MRI guidance and extent of resection in glioma surgery: a randomised, controlled trial. Lancet Oncol. 2011;12(11):997-1003.

37. Sanai N, Polley MY, McDermott MW, Parsa AT, Berger MS. An extent of resection threshold for newly diagnosed glioblastomas. J Neurosurg. 2011;115(1):3-8.

38. Gulati S, Jakola AS, Nerland US, Weber C, Solheim O. The risk of getting worse: surgically acquired deficits, perioperative complications, and functional outcomes after primary resection of glioblastoma. World Neurosurg. 2011;76(6):572-579.

39. Bashir R, Hochberg F, Oot R. Regrowth patterns of glioblastoma multiforme related to planning of interstitial brachytherapy radiation fields. Neurosurgery. 1988;23(1):27-30.

40. Jansen EP, Dewit LG, van HM, Bartelink H. Target volumes in radiotherapy for high-grade malignant glioma of the brain. Radiother Oncol. 2000;56(2):151-156.

41. Wallner KE, Galicich JH, Krol G, Arbit E, Malkin MG. Patterns of failure following treatment for glioblastoma multiforme and anaplastic astrocytoma. Int J Radiat Oncol Biol Phys. 1989;16(6): 1405-1409.

42. Aydin H, Sillenberg I, von LH. Patterns of failure following CT-based 3-D irradiation for malignant glioma. Strahlenther Onkol. 2001;177(8): 424-431.

43. Niyazi M, Siefert A, Schwarz SB, et al. Therapeutic options for recurrent malignant glioma. Radiother Oncol. 2011;98(1):1-14.

44. Mandl ES, Dirven CM, Buis DR, Postma TJ, Vandertop WP. Repeated surgery for glioblastoma multiforme: only in combination with other salvage therapy. Surg Neurol. 2008;69(5):506-509.

45. Guyotat J, Signorelli F, Frappaz D, Madarassy G, Ricci AC, Bret P. Is reoperation for recurrence of glioblastoma justified? Oncol Rep. 2000;7(4):899-904.

46. Barker FG 2nd, Chang SM, Gutin PH, et al. Survival and functional status after resection of recurrent glioblastoma multiforme. Neurosurgery. 1998;42(4):709-720. 
47. Weller M, Cloughesy T, Perry JR, Wick W. Standards of care for treatment of recurrent glioblastoma: are we there yet? Neuro Oncol. 2013;15(1):4-27.

48. Friedman HS, Prados MD, Wen PY, et al. Bevacizumab alone and in combination with irinotecan in recurrent glioblastoma. J Clin Oncol. 2009;27(28):4733-4740.

49. Kreisl TN, Kim L, Moore K, et al. Phase II trial of single-agent bevacizumab followed by bevacizumab plus irinotecan at tumor progression in recurrent glioblastoma. J Clin Oncol. 2009;27(5):740-745.

50. Tabatabai G, Stupp R, van den Bent MJ, et al. Molecular diagnostics of gliomas: the clinical perspective. Acta Neuropathol. 2010;120(5): 585-592.

51. Gorlia T, van den Bent MJ, Hegi ME, et al. Nomograms for predicting survival of patients with newly diagnosed glioblastoma: prognostic factor analysis of EORTC and NCIC trial 26981-22981/CE.3. Lancet Oncol. 2008;9(1):29-38.

52. Mirimanoff RO, Gorlia T, Mason W, et al. Radiotherapy and temozolomide for newly diagnosed glioblastoma: recursive partitioning analysis of the EORTC 26981/22981-NCIC CE3 phase III randomized trial. J Clin Oncol. 2006;24(16):2563-2569.

53. Buckner JC. Factors influencing survival in high-grade gliomas. Semin Oncol. 2003;30(6 Suppl 19):10-14.

54. Ichimura K, Pearson DM, Kocialkowski S, et al. IDH1 mutations are present in the majority of common adult gliomas but rare in primary glioblastomas. Neuro Oncol. 2009;11(4):341-347.

55. Yan H, Parsons DW, Jin G, et al. IDH1 and IDH2 mutations in gliomas. N Engl J Med. 2009;360(8):765-773.

56. Dang L, White DW, Gross S, et al. Cancer-associated IDH1 mutations produce 2-hydroxyglutarate. Nature. 2010;465(7300):966.

57. Parsons DW, Jones S, Zhang X, et al. An integrated genomic analysis of human glioblastoma multiforme. Science. 2008;321(5897):1807-1812.

58. Wick W, Hartmann C, Engel C, et al. NOA-04 randomized phase III trial of sequential chemoradiotherapy of anaplastic glioma with procarbazine, lomustine, and vincristine or temozolomide. J Clin Oncol. 2009;27(35):5874-5880.

59. Hartmann C, Hentschel B, Wick W, et al. Patients with IDH1 wild type anaplastic astrocytomas exhibit worse prognosis than IDH1-mutated glioblastomas, and IDH1 mutation status accounts for the unfavorable prognostic effect of higher age: implications for classification of gliomas. Acta Neuropathol. 2010;120(6):707-718.

60. Thon N, Eigenbrod S, Kreth S, et al. IDH1 mutations in grade II astrocytomas are associated with unfavorable progression-free survival and prolonged postrecurrence survival. Cancer. 2012;118(2):452-460.

61. Ohgaki H, Kleihues P. Genetic pathways to primary and secondary glioblastoma. Am J Pathol. 2007;170(5):1445-1453.

62. Stander M, Peraud A, Leroch B, Kreth FW. Prognostic impact of TP53 mutation status for adult patients with supratentorial World Health Organization Grade II astrocytoma or oligoastrocytoma: a long-term analysis. Cancer. 2004;101(5):1028-1035.

63. Agarwal ML, Agarwal A, Taylor WR, Stark GR. p53 controls both the G2/M and the $\mathrm{G} 1$ cell cycle checkpoints and mediates reversible growth arrest in human fibroblasts. Proc Natl Acad Sci U S A. 1995;92(18):8493-8497.

64. Cairncross G, Wang M, Shaw E, et al. Phase III trial of chemoradiotherapy for anaplastic oligodendroglioma: long-term results of RTOG 9402. J Clin Oncol. 2013;31(3):337-343.

65. van den Bent MJ, Brandes AA, Taphoorn MJ, et al. Adjuvant procarbazine, lomustine, and vincristine chemotherapy in newly diagnosed anaplastic oligodendroglioma: long-term follow-up of EORTC brain tumor group study 26951. J Clin Oncol. 2013;31(3):344-350.

66. Hegi ME, Janzer RC, Lambiv WL, et al. Presence of an oligodendroglioma-like component in newly diagnosed glioblastoma identifies a pathogenetically heterogeneous subgroup and lacks prognostic value: central pathology review of the EORTC_26981/NCIC_CE.3 trial. Acta Neuropathol. 2012;123(6):841-852.

67. Boots-Sprenger SH, Sijben A, Rijntjes J, et al. Significance of complete 1p/19q co-deletion, IDH1 mutation and MGMT promoter methylation in gliomas: use with caution. Mod Pathol. 2013;26(7):922-929.
68. Weller M, Stupp R, Hegi ME, et al. Personalized care in neuro-oncology coming of age: why we need MGMT and $1 \mathrm{p} / 19 \mathrm{q}$ testing for malignant glioma patients in clinical practice. Neuro Oncol. 2012;14 Suppl 4: iv100-iv108.

69. Cancer Genome Atlas Research Network. Comprehensive genomic characterization defines human glioblastoma genes and core pathways. Nature. 2008;455(7216):1061-1068.

70. Weller M, Felsberg J, Hartmann C, et al. Molecular predictors of progression-free and overall survival in patients with newly diagnosed glioblastoma: a prospective translational study of the German Glioma Network. J Clin Oncol. 2009;27(34):5743-5750.

71. Suzuki MM, Bird A. DNA methylation landscapes: provocative insights from epigenomics. Nat Rev Genet. 2008;9(6):465-476.

72. Irizarry RA, Ladd-Acosta C, Wen B, et al. The human colon cancer methylome shows similar hypo- and hypermethylation at conserved tissue-specific CpG island shores. Nat Genet. 2009;41(2):178-186.

73. Chen ZX, Riggs AD. DNA methylation and demethylation in mammals. J Biol Chem. 2011;286(21):18347-18353.

74. Hellman A, Chess A. Gene body-specific methylation on the active X chromosome. Science. 2007;315(5815):1141-1143.

75. Esteller M. Cancer epigenomics: DNA methylomes and histonemodification maps. Nat Rev Genet. 2007;8(4):286-298.

76. Robertson KD. DNA methylation and human disease. Nat Rev Genet. 2005;6(8):597-610.

77. Esteller M, Corn PG, Baylin SB, Herman JG. A gene hypermethylation profile of human cancer. Cancer Res. 2001;61(8):3225-3229.

78. Cadieux B, Ching TT, Vandenberg SR, Costello JF. Genome-wide hypomethylation in human glioblastomas associated with specific copy number alteration, methylenetetrahydrofolate reductase allele status, and increased proliferation. Cancer Res. 2006;66(17):8469-8476.

79. Martinez R, Martin-Subero JI, Rohde V, et al. A microarray-based DNA methylation study of glioblastoma multiforme. Epigenetics. 2009;4(4): 255-264.

80. Wu X, Rauch TA, Zhong X, et al. CpG island hypermethylation in human astrocytomas. Cancer Res. 2010;70(7):2718-2727.

81. Agnihotri S, Wolf A, Munoz DM, et al. A GATA4-regulated tumor suppressor network represses formation of malignant human astrocytomas. J Exp Med. 2011;208(4):689-702.

82. Tepel M, Roerig P, Wolter M, et al. Frequent promoter hypermethylation and transcriptional downregulation of the NDRG2 gene at 14q11.2 in primary glioblastoma. Int J Cancer. 2008;123(9):2080-2086.

83. Nakamura M, Watanabe T, Yonekawa Y, Kleihues P, Ohgaki H. Promoter methylation of the DNA repair gene MGMT in astrocytomas is frequently associated with $\mathrm{G}: \mathrm{C}->\mathrm{A}: \mathrm{T}$ mutations of the TP53 tumor suppressor gene. Carcinogenesis. 2001;22(10):1715-1719.

84. Nakamura M, Watanabe T, Klangby U, et al. p14ARF deletion and methylation in genetic pathways to glioblastomas. Brain Pathol. 2001;11(2):159-168.

85. Stone AR, Bobo W, Brat DJ, Devi NS, Van Meir EG, Vertino PM. Aberrant methylation and down-regulation of TMS1/ASC in human glioblastoma. Am J Pathol. 2004;165(4):1151-1161.

86. Kosla K, Pluciennik E, Kurzyk A, et al. Molecular analysis of WWOX expression correlation with proliferation and apoptosis in glioblastoma multiforme. J Neurooncol. 2011;101(2):207-213.

87. Waha A, Güntner S, Huang TH, et al. Epigenetic silencing of the protocadherin family member PCDH-gamma-A11 in astrocytomas. Neoplasia. 2005;7(3):193-199.

88. Lindemann C, Hackmann O, Delic S, Schmidt N, Reifenberger G, Riemenschneider MJ. SOCS3 promoter methylation is mutually exclusive to EGFR amplification in gliomas and promotes glioma cell invasion through STAT3 and FAK activation. Acta Neuropathol. 2011;122(2): 241-251.

89. Alonso MM, Diez-Valle R, Manterola L, et al. Genetic and epigenetic modifications of Sox 2 contribute to the invasive phenotype of malignant gliomas. PLoS One. 2011;6(11):e26740.

90. Uhlmann K, Rohde K, Zeller C, et al. Distinct methylation profiles of glioma subtypes. Int $J$ Cancer. 2003;106(1):52-59. 
91. Verhaak RG, Hoadley KA, Purdom E, et al. Integrated genomic analysis identifies clinically relevant subtypes of glioblastoma characterized by abnormalities in PDGFRA, IDH1, EGFR, and NF1. Cancer Cell. 2010;17(1):98-110.

92. Noushmehr H, Weisenberger DJ, Diefes K, et al. Identification of a $\mathrm{CpG}$ island methylator phenotype that defines a distinct subgroup of glioma. Cancer Cell. 2010;17(5):510-522.

93. Figueroa ME, Abdel-Wahab O, Lu C, et al. Leukemic IDH1 and IDH2 mutations result in a hypermethylation phenotype, disrupt TET2 function, and impair hematopoietic differentiation. Cancer Cell. 2010;18(6):553-567.

94. Williams K, Christensen J, Pedersen MT, et al. TET1 and hydroxymethylcytosine in transcription and DNA methylation fidelity. Nature. 2011;473(7347):343-348.

95. Guo JU, Su Y, Zhong C, Ming GL, Song H. Hydroxylation of 5-methylcytosine by TET1 promotes active DNA demethylation in the adult brain. Cell. 2011;145(3):423-434.

96. Lu C, Ward PS, Kapoor GS, et al. IDH mutation impairs histone demethylation and results in a block to cell differentiation. Nature 2012;483(7390):474-478.

97. Xu W, Yang H, Liu Y, et al. Oncometabolite 2-hydroxyglutarate is a competitive inhibitor of alpha-ketoglutarate-dependent dioxygenases. Cancer Cell. 2011;19(1):17-30.

98. Jin SG, Jiang Y, Qiu R, et al. 5-Hydroxymethylcytosine is strongly depleted in human cancers but its levels do not correlate with IDH1 mutations. Cancer Res. 2011;71(24):7360-7365.

99. Kraus TF, Globisch D, Wagner M, et al. Low values of 5-hydroxymethylcytosine $(5 \mathrm{hmC})$, the "sixth base," are associated with anaplasia in human brain tumors. Int J Cancer. 2012;131(7): 1577-1590.

100. Pegg AE. Repair of O(6)-alkylguanine by alkyltransferases. Mutat Res. 2000;462(2-3):83-100.

101. Gerson SL. MGMT: its role in cancer aetiology and cancer therapeutics. Nat Rev Cancer. 2004;4(4):296-307.

102. Preusser M, Charles Janzer R, Felsberg J, et al. Anti-O6-methylguanine-methyltransferase (MGMT) immunohistochemistry in glioblastoma multiforme: observer variability and lack of association with patient survival impede its use as clinical biomarker. Brain Pathol. 2008;18(4):520-532.

103. Hegi ME, Diserens AC, Gorlia T, et al. MGMT gene silencing and benefit from temozolomide in glioblastoma. $N$ Engl J Med. 2005;352(10):997-1003.

104. Ellingson BM, Cloughesy TF, Pope WB, et al. Anatomic localization of O6-methylguanine DNA methyltransferase (MGMT) promoter methylated and unmethylated tumors: a radiographic study in 358 de novo human glioblastomas. Neuroimage. 2012;59(2):908-916.

105. Levner I, Drabycz S, Roldan G, de Robles P, Cairncross JG, Mitchell R. Predicting MGMT methylation status of glioblastomas from MRI texture. Med Image Comput Comput Assist Interv. 2009;12(Pt 2):522-530.

106. Romano A, Calabria LF, Tavanti F, et al. Apparent diffusion coefficient obtained by magnetic resonance imaging as a prognostic marker in glioblastomas: correlation with MGMT promoter methylation status. Eur Radiol. 2013;23(2):513-520.

107. Park CK, Kim J, Yim SY, et al. Usefulness of MS-MLPA for detection of MGMT promoter methylation in the evaluation of pseudoprogression in glioblastoma patients. Neuro Oncol. 2011;13(2):195-202.

108. Brandes AA, Franceschi E, Tosoni A, et al. MGMT promoter methylation status can predict the incidence and outcome of pseudoprogression after concomitant chemoradiotherapy in newly diagnosed glioblastoma patients. J Clin Oncol. 2008;26(13):2192-2197.

109. Niyazi M, Schnell O, Suchorska B, et al. FET-PET assessed recurrence pattern after radio-chemotherapy in newly diagnosed patients with glioblastoma is influenced by MGMT methylation status. Radiother Oncol. 2012;104(1):78-82.

110. Drabycz S, Roldán G, de Robles P, et al. An analysis of image texture, tumor location, and MGMT promoter methylation in glioblastoma using magnetic resonance imaging. Neuroimage. 2010;49(2):1398-1405.
111. Ahluwalia MS. American Society of Clinical Oncology. 2011 CNS tumors update. Expert Rev Anticancer Ther. 2011;11(10):1495-1497.

112. Reifenberger G, Hentschel B, Felsberg J, et al. Predictive impact of MGMT promoter methylation in glioblastoma of the elderly. Int $J$ Cancer. 2012;131(6):1342-1350.

113. Gilbert MR, Wang M, Aldape K, et al. RTOG 0525: a randomized phase III trial comparing standard adjuvant temozolomide (TMZ) with a dose-dense (dd) schedule in newly diagnosed glioblastoma (GBM). Neuro Oncol. 2011;13:51.

114. Baur M, Preusser M, Piribauer M, et al. Frequent MGMT (0(6)methylguanine-DNA methyltransferase) hypermethylation in longterm survivors of glioblastoma: a single institution experience. Radiol Oncol. 2010;44(2):113-120.

115. Felsberg J, Thon N, Eigenbrod S, et al. Promoter methylation and expression of MGMT and the DNA mismatch repair genes MLH1, MSH2, MSH6 and PMS2 in paired primary and recurrent glioblastomas. Int J Cancer. 2011;129(3):659-670.

116. van den Bent MJ, Dubbink HJ, Sanson M, et al. MGMT promoter methylation is prognostic but not predictive for outcome to adjuvant PCV chemotherapy in anaplastic oligodendroglial tumors: a report from EORTC Brain Tumor Group Study 26951. J Clin Oncol. 2009;27(35): 5881-5886

117. Bady P, Sciuscio D, Diserens AC, et al. MGMT methylation analysis of glioblastoma on the Infinium methylation BeadChip identifies two distinct $\mathrm{CpG}$ regions associated with gene silencing and outcome, yielding a prediction model for comparisons across datasets, tumor grades, and CIMP-status. Acta Neuropathol. 2012;124(4):547-560.

118. Della Puppa A, Persano L, Masi G, et al. MGMT expression and promoter methylation status may depend on the site of surgical sample collection within glioblastoma: a possible pitfall in stratification of patients? J Neurooncol. 2012;106(1):33-41.

119. Herman JG, Graff JR, Myohanen S, Nelkin BD, Baylin SB Methylation-specific PCR: a novel PCR assay for methylation status of CpG islands. Proc Natl Acad Sci U S A. 1996;93(18):9821-9826.

120. Christians A, Hartmann C, Benner A, Meyer J, et al. Prognostic value of three different methods of MGMT promoter methylation analysis in a prospective trial on newly diagnosed glioblastoma. PLoS One. 2012;7(3):e33449.

121. McDonald KL, Aw G, Kleihues P. Role of biomarkers in the clinical management of glioblastomas: what are the barriers and how can we overcome them? Front Neurol. 2012;3:188.

122. Esteller M, Garcia-Foncillas J, Andion E, et al. Inactivation of the DNA-repair gene MGMT and the clinical response of gliomas to alkylating agents. $N$ Engl J Med. 2000;343(19):1350-1354.

123. Mollemann M, Wolter M, Felsberg J, Collins VP, Reifenberger G. Frequent promoter hypermethylation and low expression of the MGMT gene in oligodendroglial tumors. Int $J$ Cancer. 2005;113(3): 379-385.

124. Grasbon-Frodl EM, Kreth FW, Ruiter M, et al. Intratumoral homogeneity of MGMT promoter hypermethylation as demonstrated in serial stereotactic specimens from anaplastic astrocytomas and glioblastomas. Int J Cancer. 2007;121(11):2458-2464.

125. Malley DS, Hamoudi RA, Kocialkowski S, Pearson DM, Collins VP, Ichimura K. A distinct region of the MGMT CpG island critical for transcriptional regulation is preferentially methylated in glioblastoma cells and xenografts. Acta Neuropathol. 2011;121(5):651-661.

126. van Vlodrop IJ, Niessen HE, Derks S, et al. Analysis of promoter CpG island hypermethylation in cancer: location, location, location! Clin Cancer Res. 2011;17(13):4225-4231.

127. Kreth S, Thon N, Eigenbrod S, et al. O-methylguanine-DNA methyltransferase (MGMT) mRNA expression predicts outcome in malignant glioma independent of MGMT promoter methylation. PLoS One. 2011;6(2):e17156.

128. Lalezari S, Chou AP, Tran A, et al. Combined analysis of O6methylguanine-DNA methyltransferase protein expression and promoter methylation provides optimized prognostication of glioblastoma outcome. Neuro Oncol. 2013;15(3):370-381. 
129. Kreth S, Limbeck E, Hinske LC, et al. In human glioblastomas transcript elongation by alternative polyadenylation and miRNA targeting is a potent mechanism of MGMT silencing. Acta Neuropathol. 2013;125(5):671-681.

130. Agnihotri S, Gajadhar AS, Ternamian C, et al. Alkylpurine-DNA-Nglycosylase confers resistance to temozolomide in xenograft models of glioblastoma multiforme and is associated with poor survival in patients. J Clin Invest. 2012;122(1):253-266.

131. Weller M, Platten M, Roth P, Wick W. Geriatric neuro-oncology: from mythology to biology. Curr Opin Neurol. 2011;24(6):599-604.

132. Laperriere N, Weller M, Stupp R, et al. Optimal management of elderly patients with glioblastoma. Cancer Treat Rev. 2013;39(4): 350-357.

133. Malmström A, Grønberg BH, Marosi C, et al. Temozolomide versus standard 6-week radiotherapy versus hypofractionated radiotherapy in patients older than 60 years with glioblastoma: the Nordic randomised, phase 3 trial. Lancet Oncol. 2012;13(9):916-926.

134. Grossman SA, Ye X, Chamberlain M, et al. Talampanel with standard radiation and temozolomide in patients with newly diagnosed glioblastoma: a multicenter phase II trial. J Clin Oncol. 2009;27(25): 4155-4161.
135. Peereboom DM, Shepard DR, Ahluwalia MS, et al. Phase II trial of erlotinib with temozolomide and radiation in patients with newly diagnosed glioblastoma multiforme. J Neurooncol. 2010;98(1): 93-99.

136. Weiler M, Hartmann C, Wiewrodt D, et al. Chemoradiotherapy of newly diagnosed glioblastoma with intensified temozolomide. Int $J$ Radiat Oncol Biol Phys. 2010;77(3):670-676.

137. Lai A, Tran A, Nghiemphu PL, et al. Phase II study of bevacizumab plus temozolomide during and after radiation therapy for patients with newly diagnosed glioblastoma multiforme. J Clin Oncol. 2011;29(2): 142-148.

138. Stupp R, Hegi ME, Neyns B, et al. Phase I/IIa study of cilengitide and temozolomide with concomitant radiotherapy followed by cilengitide and temozolomide maintenance therapy in patients with newly diagnosed glioblastoma. J Clin Oncol. 2010;28(16): 2712-2718.

139. Colman H, Zhang L, Sulman EP, et al. A multigene predictor of outcome in glioblastoma. Neuro Oncol. 2010;12(1):49-57.
OncoTargets and Therapy

\section{Publish your work in this journal}

OncoTargets and Therapy is an international, peer-reviewed, open access journal focusing on the pathological basis of all cancers, potential targets for therapy and treatment protocols employed to improve the management of cancer patients. The journal also focuses on the impact of management programs and new therapeutic agents and protocols on

\section{Dovepress}

patient perspectives such as quality of life, adherence and satisfaction The manuscript management system is completely online and includes a very quick and fair peer-review system, which is all easy to use. Visit http://www.dovepress.com/testimonials.php to read real quotes from published authors. 